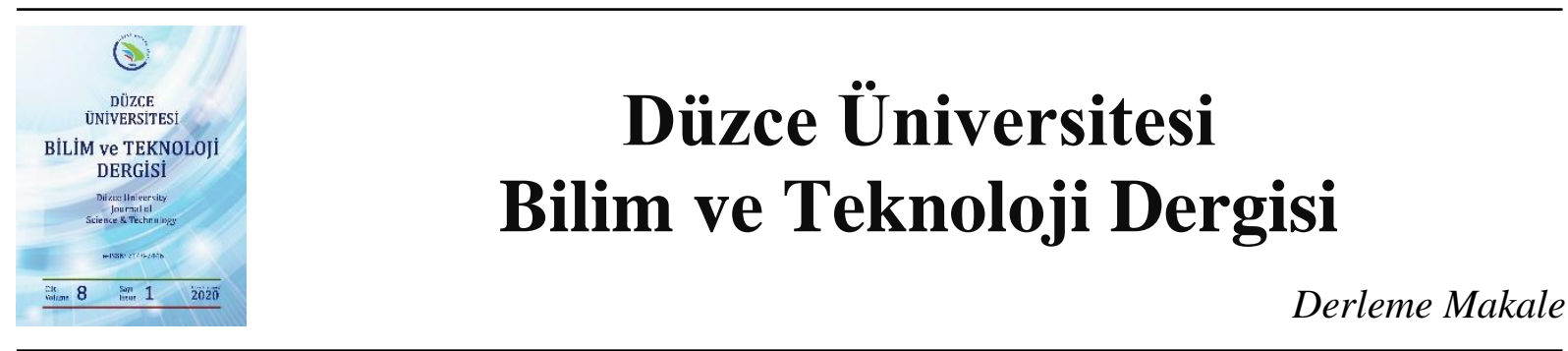

\section{Magnezyum ve Alaşımlarının Toz Metalurjisi İşlemleri}

\author{
Azim GÖKÇE ${ }^{a, *}$ \\ ${ }^{a}$ Metalurji ve Malzeme Mühendisliği Bölümü, Teknoloji Fakültesi, Sakarya Uygulamalı Bilimler Üniversitesi, \\ Sakarya, TÜRKIYE \\ * Sorumlu yazarin e-posta: azimg@subu.edu.tr \\ DOI: $10.29130 /$ dubited.569098
}

\begin{abstract}
ÖZET
$\mathrm{Bu}$ çalışmada, günden güne daha geniş alanlarda kullanılan magnezyum tozmetal alaşımların endüstriyel uygulamalarda kullanılabilirliği incelenmiştir. Bu malzemenin hegzagonal sıkı paket kafes yapısından dolayı plastik deformasyonunda yaşanan zorlukları aşmak için geleneksel plastik deformasyon yöntemleri yerine toz metalurjisi yöntemi ile şekillendirilebilirliği hakkında literatürde bulunan çalışmalar derlenmiştir. Özellikle magnezyum partiküllerinin üretimi sürecinde oluşan yüzey oksidi tabakasının elimine edilmesi için kullanılabilecek yöntemlerle ilgili çalışmaların bulguları özetlenmiştir. Sonuç olarak press-sinter yöntemine göre daha sofistike yöntemler veya ikincil işlemler kullanılması durumunda döküm alaşımlarına göre daha yüksek dayanım gösteren $\mathrm{Mg}$ alaşımlarının üretiminin mümkün olduğu ve gelişen partikül malzeme üretim yöntemleri (Seçici lazer sinterleme, direkt enerji biriktirme gibi) ile birlikte yakın gelecekte tozmetal magnezyum alaşımlarının daha geniş alanlarda kullanılacağı öngörülmektedir.
\end{abstract}

Anahtar Kelimeler: Magnezyum, Toz metalurjisi, Sinterleme

\section{Powder Metallurgy Processing of Magnesium and Its Alloys}

\begin{abstract}
In this study, the usability of powder metal magnesium alloys in industrial applications was investigated. It is well known that there are difficulties in the plastic deformation of magnesium, due to its hexagonal closed package crystal structure. So it is thought that powder metallurgy can be used to overcome these aforementioned problems. Hence, the studies on the powder metallurgy processing of magnesium alloys were compiled. The findings of the studies on eliminating the surface oxide layer formed during the production of magnesium particles are summarized. As a result, when more sophisticated methods or secondary processes are used rather than presssinter methods, it is possible to produce Mg alloys with higher strength than that of casted counterparts. Also, it is expected that in the near future along with the development of new kind of particulate material processing methods (such as selective laser sintering, direct energy deposition) $\mathrm{Mg}$ alloys will be used in much greater amounts.
\end{abstract}

Keywords: Magnesium, Powder Metallurgy, Sintering 


\section{I.GIRISS}

2017 yılında yayınlanan bir rapora göre dünya üzerinde taşımacılık işlemleri için günde yaklaşı 55 milyon varil petrol kullanılmaktadır ve 2040 yılında bu değerin 70 milyon varilden daha yüksek olmas beklenmektedir [1]. Dünya üzerindeki petrol kaynakları günden güne tükenmektedir. Bununla birlikte, sera etkisi yapan gazların başlıca kaynağını taşımacılık sektörü oluşturmaktadır. Sera etkisi yapan gazların başlıcası $\mathrm{CO}_{2}$ 'dir. Doğaya salınan sera gazlarının \% 62'sini fosil yakıtlardan dolayı oluşan $\mathrm{CO}_{2}$ oluşturmaktadır [2]. Dünyada kullanılan enerjinin \% 80.3'ünün kaynağı fosil yakıtlardır ve fosil yakıtlardan elde edilen enerjinin \% 57.7'si taşımacılık sektörlerinde kullanılmaktadır [3]. 2008 yılında yapılan bir simülasyon günümüzdeki fosil enerji kaynaklarının yaklaşık 50 yıl içinde tükeneceğini ortaya koymuştur [4]. Öngörülerin ve simülasyonların günümüzdeki fosil yakıt tüketimini temel alarak yapılmasından dolayı bu değerlerde sapma meydana getirecek bazı teknolojik gelişmeler bulunmaktadır. Yenilenebilir enerji kaynaklarının endüstriyel seviyede kullanılabilir hale gelmesi ve daha yüksek enerji tasarrufu sağlayan araçların geliştirilmesi ile fosil yakıtların daha uzun süre kullanılabilir hale getirilmesi mümkündür.

Daha düşük miktarda fosil yakıt tüketimi sağlamak için geliştirilen yöntemlerden biri de en büyük fosil yakıt tüketicisi olan taşımacılık araçlarının ağırlıklarının düşürülmesidir. Dizel motora sahip bir araçta 100 kg'lık bir ağırlık azalması 100 km'de 0.15 ila 0.3 litrelik bir yakıt tasarrufuna sebep olmaktadır [5]. Yapılan araştırmalar özellikle yakıt fiyatlarının anormal olarak arttığı 1975 senesinden 2000'lerin başına kadar araç ağırlıklarının düzenli şekilde artmasına rağmen son 15 yılda araç ağırlıklarının nerdeyse sabit kaldığını göstermektedir (Şekil 1). Bununla birlikte gelişen teknoloji ile birlikte araçların ürettikleri güç $\% 80$ artmıştır.

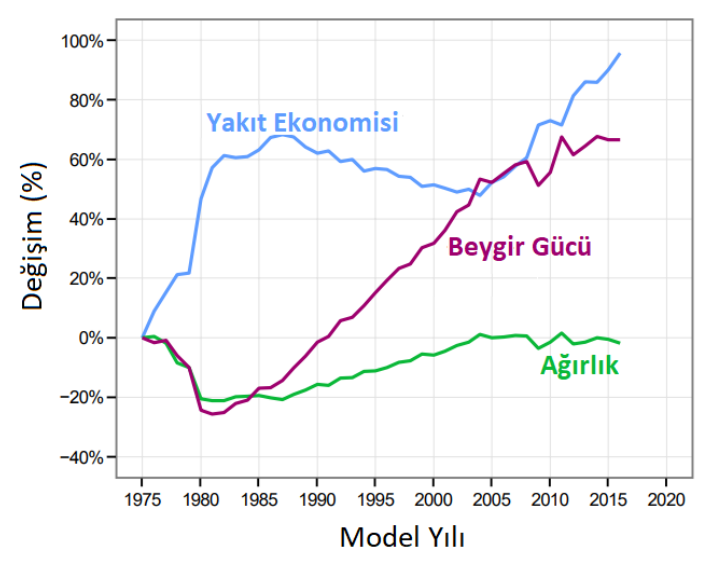

Şekil 1. Ortalama binek Amerikan arabasının yıllara göre ağırlık değişimi [6]

Araçların tasarımı yapılırken göz önünde bulundurulması gereken bir diğer konu da aracın güvenli olmasıdır. 1980'li yılların sonunda yapılan bir çalışma daha ağır araçların karıştı̆̆ olası bir kazada daha az ölüm meydana geldiğini belirtmektedir [7]. Ortalama bir aracın ağırlığının \% 70'ini çelik malzemeler oluşturmaktadır [8]. Her ne kadar yeni nesil çeliklerin kullanılmasıyla birlikte daha ince kesitli çelik malzemelerle araç ağırlığında bir miktar düşme sağlanmış olsa da [9], [10], günümüzde çeliğin yerini alabilecek nitelikte gerekli fiziksel ve mekanik özellikleri gösterebilecek hafif malzemelerle ilgili çalışmalar otomotiv üreticilerinin başlıca odak noktalarından birini oluşturmaktadır. Özellikle çelik malzemelerin kullanım alanını düşürmek amaçlandığı zaman gerekli dayanımı polimer esaslı malzemelerin sağlaması mümkün değildir. Dolayısıyla alternatif olarak hafif alaşımlar (Şekil 2) ve bu alaşımların matris olarak kullanıldığı kompozit malzemeler ele alınmaktadır [11], [12]. Her ne kadar hafif metaller olarak alüminyum, magnezyum ve titanyum tanımlanmış olsa da [13] titanyumun yüksek maliyet nedeniyle yüksek ağırlık ve hacim gerektiren uygulamalarda kullanımı tercih edilmemektedir. Üstelik titanyumun özgül ağırlığı alüminyumun 1.67 katı magnezyumun 2.65 katıdır. 


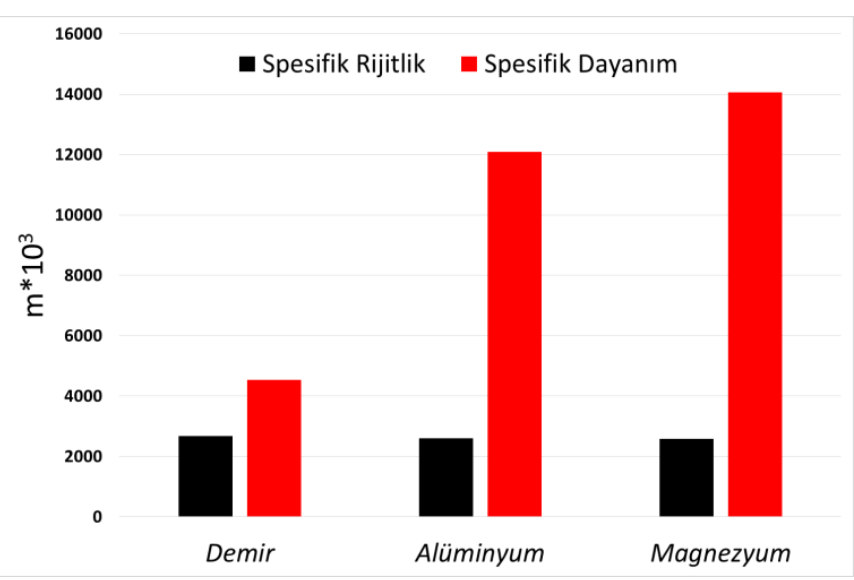

Şekil 2. Otomotiv sektöründe kullanılan bazı metallerin spesifik rijitlik ve dayanım klyaslaması [14]

Alüminyum alaşımları, alüminyumun magnezyuma göre nispeten daha yüksek dayanımı, daha düşük hammadde fiyatı ve şekillendirilmesinin daha kolay olmasından dolayı otomotiv sektöründe daha erken kullanılmaya başlanmıştır ve kullanım alanları daha geniştir [15], [16]. Spesifik dayanımının (dayanım/yoğunluk) daha yüksek olmasına rağmen kristal kafes yapısından dolayı magnezyumun daha zor şekillendirilmesi, magnezyumun endüstriyel uygulamalarda kullanılmasını zorlaştırmaktadır. Magnezyumun hegzagonal sıkı paket yapıda olmasından dolayı bu malzemede kayma sistemi sayıs1 sadece 2 tanedir. Oysa alüminyum kristal yapısı yüzey merkezli kübiktir ve bu malzemede 12 kayma sistemi bulunmaktadır. Kayma sistemi sayısı arttıkça malzemenin daha kolay plastik deformasyona uğradığı bilinmektedir, dolayısıyla magnezyum alaşımlarının plastik deformasyonu alüminyumdan farklıdır [17]. Otomotiv sektöründe sıklıkla ihtiyaç duyulan yassı mamul haline getirilmesi için haddeleme veya yapısal uygulamalar için ekstrüzyon gibi işlemler sınırlanmaktadır. Magnezyum alaşımlarının döküm yoluyla üretilmesinde ise bu malzemenin oksijene karşı yüksek afinitesinden dolayı koruyucu atmosfer kullanılması gereklidir [18]-[21]. Üstelik geleneksel gravite döküm yöntemleri ile karmaşı şekilli parça üretiminin mümkün olmaması nedeniyle yüksek basınçlı döküm işlemi kullanılsa da bu yöntemde üretilebilecek parça büyüklüğü kısıtlıdır [22]. Magnezyumun başlıca avantaj ve dezavantajları Tablo 1'de verilmiştir.

Tablo 1. Yapısal malzeme olarak magnezyumun avantajlarl ve dezavantajlarl [23]

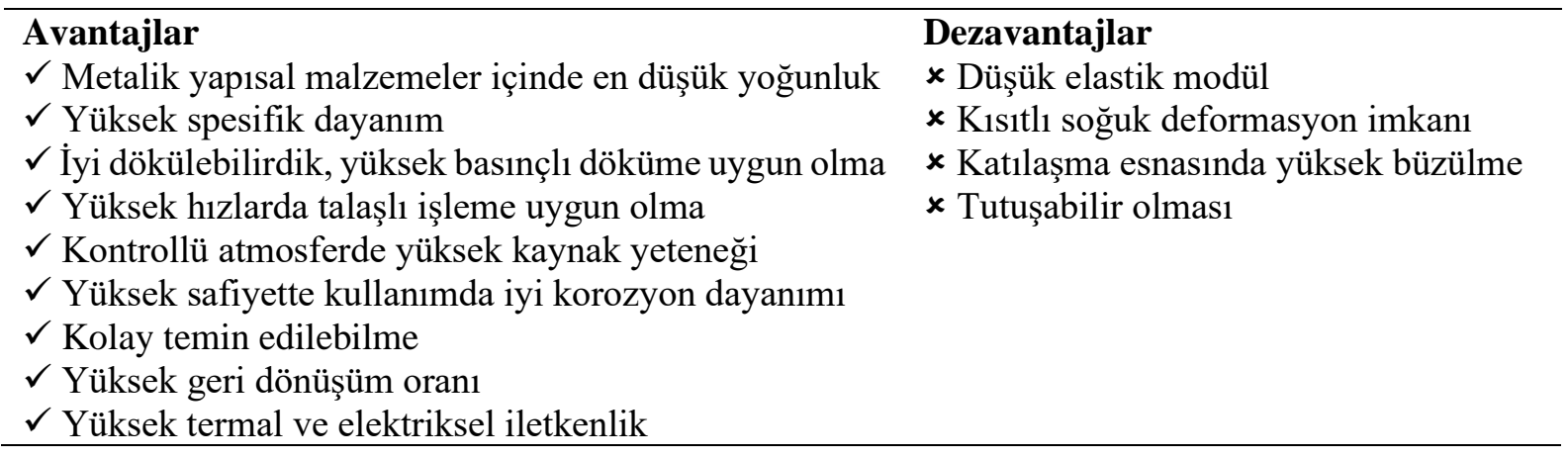

Toz metalurjisi (TM) yöntemi diğer imal usullerine nispeten daha yeni bir üretim yöntemidir ve üreticilerin enerji ve hammadde giderlerinden büyük miktarda tasarruf etmesini sağlar [24]. Yöntem partikül haline getirilmiş metal veya alaşımların basınç altında şekillendirilmesi ve ergime sıcaklıklarının altındaki bir sıcaklıkta tutulması esasına dayanmaktadır [25]. Örneğin tüm araçlarda bulunan bir yağ pompası dişlisinin (Şekil 3) üretim yöntemi talaşlı işlemler yerine TM ile yapıldığında her bir parçanın üretimi için gereken enerji miktarı 1.01 MJ'den 0.50 MJ'ye düşmektedir [26]. Belirtilen parçanın ağırlığ 73 gramdır. Talaşlı işlemde bu parça her her bir parça için kullanılan hammadde 192 gramken TM yönteminde 76.5 gram toz ile parça üretilebilmektedir. Dolayısıyla talaşlı işlemde hammaddenin yarısından fazlası ürüne dönüşemezken TM yönteminde parçanın \% 95'ten daha fazlası 
ürün haline dönüşmektedir [26]. TM yöntemiyle üretilen parçalarda yüksek boyut hassasiyeti bulunmaktadır, üretim sonrası boyut hassasiyeti için ikincil işlemlere gerek duyulmamaktadır. TM yönteminin bir başka avantajı ise kontrollü gözenek oluşumuna imkan sağlamasıdır. Bu yöntemle birlikte örneğin filtre amaçlı parçalar kolaylıkla üretilebilmektedir. Ayrıca TM yöntemi ergitilmesi mümkün olmayan WC gibi bazı malzemelerden parça üretimi için kullanılabilecek tek yöntemdir.

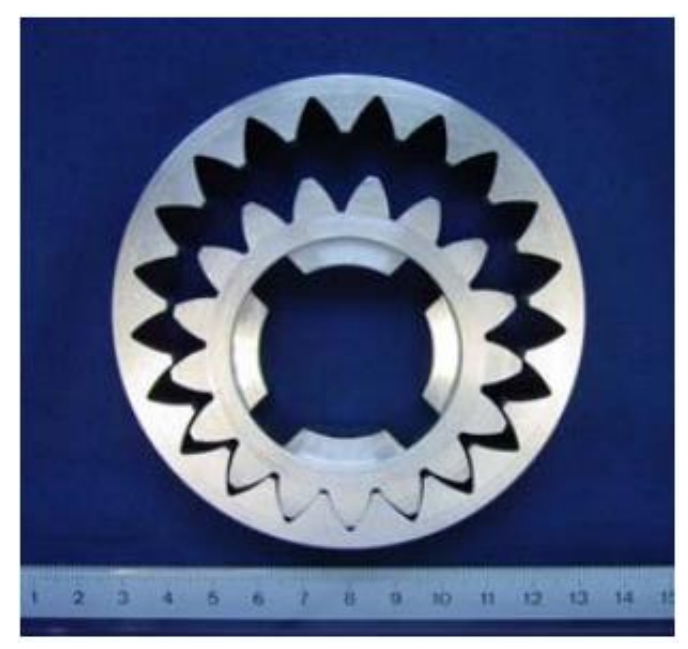

Şekil 3. TM ile üretilmiş bir yağ pompası dişlisi seti [27]

Magnezyum alaşımlarının ürün haline dönüştürülmesinde kristal kafes yapısı nedeniyle yaşanan zorlukların TM yöntemiyle aşılması mümkündür. Özellikle günümüzde sıklıkla kullanılmaya başlanan katmanlı üretim teknolojilerinin gelecekte partikül malzemeler kullanılarak yapılan üretim miktarını çok daha artırması beklenmektedir. Bu çalışmada saf magnezyum ve $\mathrm{Mg}$-Al alaşımlarının TM ile üretim süreçlerinde yaşanan gelişmeler özetlenmiş ve elde edilen bulgular derlenmiştir. Çalışmanın özellikle TM ve hafif alaşımlar alanında çalışan araştırmacılar için değerli bir kaynak olacağı düşünülmektedir.

\section{A. MgO TABAKASI}

Magnezyum tozlarının sinterlenmesinde en büyük engel tozların yüzeyinde bulunan oldukça kararlı oksit tabakasıdır (Şekil 4). Her ne kadar bu oksit tabakası çok ince (5-6 nm [28]) olsa da kararlı yapıda olmas1 sebebiyle saf magnezyuma indirgenmesi zordur. Bu tabaka sebebiyle magnezyum partikülleri arasında difüzyon mümkün olmayacağı için partiküller arasında boyun oluşumu gerçekleşmez. Dolayısıyla gözeneklerin kapanması da mümkün olmaz ve sinterleme gerçekleşmez. Yine partikül yüzeylerinde bir miktar da $\mathrm{Mg}(\mathrm{OH})_{2}$ ve $\mathrm{MgCO}_{3}$ bulunduğu da bilinmektedir ancak bu bileşenler sinterleme sıcaklığının daha altındaki sıcaklıklarda $\left(260^{\circ} \mathrm{C}\right.$ ve $\left.450{ }^{\circ} \mathrm{C}\right)$ bozunarak $\mathrm{MgO}$ 'ya dönüşürler [29].

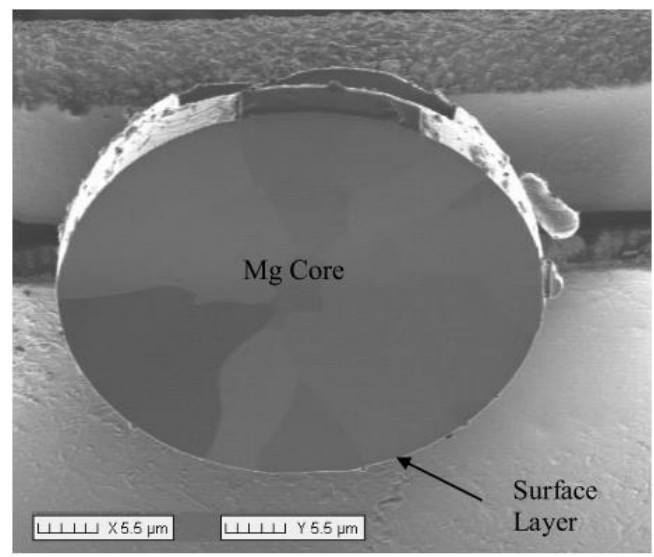

Şekil 4. Magnezyum tozu yüzeyindeki MgO tabakası [30] 
Demir esaslı tozların sinterlenmesinde hidrojen veya parçalanmış amonyak atmosferi kullanılarak demir üzerindeki oksit tabakasının indirgenmesi mümkündür [31]. $\mathrm{MgO}$ tabakasının oldukça düşük olan oluşum entalpisi $(-601 \mathrm{~kJ} / \mathrm{mol})$ sebebiyle herhangi bir indirgeyici atmosfer kullanılarak bu tabakanın indirgenmesi mümkün değildir. Başka bir hafif alaşım olan alüminyumda da benzer şekilde partiküller üzerinde oksit tabakası bulunmaktadır ve indirgeyici atmosfer kullanılarak indirgenmesi termodinamik sebeplerle mümkün değildir [24], [32]. Alüminyum için yüzey oksidini indirgemek için oluşum entalpisi daha düşük olan magnezyum kullanılmaktadır [33]. Aynı sebeple magnezyumun yüzey oksidini indirgemek için oksijene afinitesi magnezyumdan daha fazla olan ve daha düşük oksit oluşum entalpisine sahip bir element kullanılması zorunludur. Magnezyum yüzeyindeki oksit tabakasını magnezyuma indirgemek için gerekli termodinamik koşulları sağlayan bazı elementler ve olası reaksiyonlar aşağıda verilmiştir [34].

$\begin{array}{lll}\mathrm{MgO}+\mathrm{Ca} & \rightarrow & \mathrm{Mg}+\mathrm{CaO} \\ \mathrm{MgO}+\mathrm{Be} & \rightarrow & \mathrm{Mg}+\mathrm{BeO} \\ 3 \mathrm{MgO}+2 \mathrm{Yb} & \rightarrow & 3 \mathrm{Mg}+\mathrm{Yb}_{2} \mathrm{O}_{3} \\ 3 \mathrm{MgO}+2 \mathrm{Y} & \rightarrow & 3 \mathrm{Mg}+\mathrm{Y}_{2} \mathrm{O}_{3} \\ 3 \mathrm{MgO}+2 \mathrm{Dy} & \rightarrow & 3 \mathrm{Mg}+\mathrm{Dy}_{2} \mathrm{O}_{3}\end{array}$

Sinterlemenin gerçekleşmesi için yüzey oksidinden kaçınmanın bir diğer yolu oksit tabakası ile çevrelenmiş olan magnezyumun oksit tabakası içine difüzyonu ile bir diğer partikül içindeki magnezyuma temas etmesinin sağlanmasıdır. Ancak, magnezyumun magnezyum oksit içindeki difüzyon katsayısının çok düşük olması bu işlem için gereken zamanın çok uzun olmasını sağlar. $\mathrm{Bu}$ sebeple bu yöntem endüstriyel uygulamalar için kullanılabilir değildir.

Toz şekillendirme (presleme, kompaktlama) sırasında uygulanan fiziksel kuvvetle gevrek yapıda olan magnezyum oksit tabakasının kırılacağı bilinmektedir[24] ancak şekillendirme soy atmosfer altında yapılmıyorsa eş zamanlı olarak tekrar oksit tabakası oluşacağı için bu yöntemin kullanılması da mümkün değildir. Aynı şekilde eğer sinterlenecek metalin termal genleşme katsayısı oksidinin termal genleşme katsayısından daha fazlaysa sinterleme sırasında artan sicaklıkla birlikte metalin daha fazla genleşerek oksit tabakası üstünde çatlaklar oluşturması ve bu çatlaklar sebebiyle boyunlar oluşturmasını mümkün hale gelmektedir.

\section{Mg ALASIMLARININ SINTERLEME CALISMALARI}

\section{A. SAF Mg}

TM süreçlerinde sinterleme işlemlerinde eğer tek bir element kullanılıyorsa veya sinterleme sıcaklığı herhangi bir sıvı fazın oluşumu için yeterli değilse sinterleme türü "katı faz sinterleme" olarak adlandırılır [25]. Bu tip sinterlemede partiküller arasında atom difüzyonu sonucu ortaya çıkan boyunlar ve bu boyunların genişleyerek gözeneklerin kapanması esastır. Yüksek seviyede yoğunlaşma için gerekli süre sıvı faz sinterlemeye göre daha uzundur. Saf Mg içine herhangi bir alaşım elementi veya sinterleme yardımcısı eklenmeden yapılan sinterleme katı faz sinterleme olacaktır. Dolayısıyla herhangi bir oksit indirgeyici kullanılmaması dolayısıyla $\mathrm{Mg}$ yüzeyindeki oksit tabakası atom difüzyonu için bariyer etkisi yapacaktır. Bu öngörüyü doğrular şekilde, Osman Sinan Gökçe, Rıdvan Yamanoğlu danışmanlığında yaptı̆̆ çalışmada [35] saf $\mathrm{Mg}$ tozlarını vakum altında sıcak presleme ile şekillendirmelerine rağmen mikroyapıda partikül sınırlarında yüksek miktarda oksijen tespit etmişlerdir. Çalışmalarında sıcak presleme yönteminin bir avantajı olarak bazı bölgelerde yüzey oksidini kırdıkları ve kontrollü atmosfer kullanmaları nedeniyle yeniden oluşmasına izin vermeden sinterlemeyi tamamlayarak yüksek yoğunluklar elde ettiklerini rapor etmişlerdir. Taşkın vd. [36] ise nispeten daha yüksek tane boyutuna sahip magnezyum talaşlarından üretilen parçaların karakterizasyonunu esas alan çalışmamalarında yüzey oksidinin olumsuz etkisini bertaraf etmek için ekstrüzyon işlemini tercih etmişlerdir. Çalışmalarda her ne kadar yüksek yoğunluk elde edilmiş olsa da partikül sınırlarında 
bulunan oksijen sebebiyle döküm ve işlenmiş Mg alaşımlarının dayanım seviyelerine ulaşılamamıştır. Bununla birlikte sertlik değerleri döküm alaşımlarla kıyaslanabilir seviyededir [35].

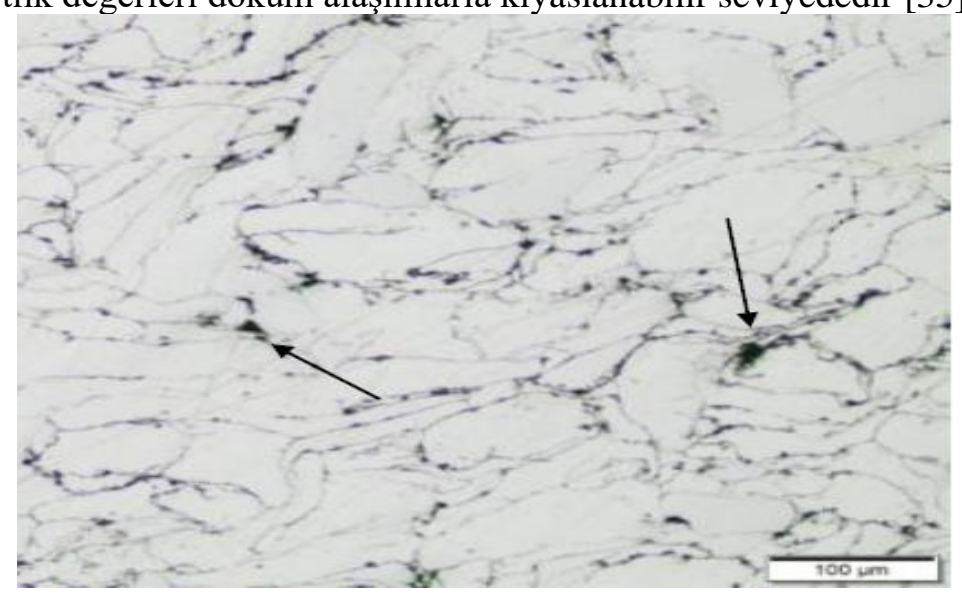

Şekil 5. Sıcak preslenmiş saf Mg mikroyapı görüntüsü [35]

Iwoaka ve Nakamura [37] geleneksel pres-sinter yöntemiyle ürettikleri saf Mg numunelerin özelliklerini inceledikleri çalışmalarında $489 \mathrm{MPa}$ ile şekillendirdikleri numuneleri 326 ve $600{ }^{\circ} \mathrm{C}$ 'de sinterlemişler sırasıyla 45 ve $65 \mathrm{MPa}$ eğme dayanımı elde edebilmişlerdir. Aynı numuneleri sıcak presleme ile preslediklerinde ise eğme dayanımı 75 ila $110 \mathrm{MPa}$ olarak ölçülmüsşür. Yazarlar, sıcak presleme ile daha yüksek dayanım elde edilmesini, yüksek sıcaklıklarda oksit filminin kısmi olarak bozunarak partiküller arasında boyun oluşumu için uygun şartların oluşmasına bağlamışlardır. Brezina vd. [38] saf magnezyum tozlarının oda sıcaklığında ve yüksek sıcaklıklarda şekillendirilmesinin mikroyapı ve mekanik özelliklere etkisini incelemişlerdir. Çalışma yüksek sıcaklıklarda yapılan şekillendirme ile çok daha yüksek eğme dayanımı elde edilebileceğini gösterse de belli bir sıcaklık üstünde dayanım değerlerinde düşme tespit edilmiştir. En yüksek eğme dayanımı yaklaşı $250 \mathrm{MPa}$ 'dır ve $400{ }^{\circ} \mathrm{C}$ 'de 400 MPa basınç altında şekillendirme ile elde edilmiştir [38]. Yüksek sıcaklıklarda eğme dayanımında olan düşmenin sebebi olarak tane büyümesi veya deformasyondan dolayı oluşan dislokasyon yoğunluğundaki düşme gösterilebilir. Burke vd. [39] saf Mg tozlarını press-sinter ve soğuk izostatik presleme ile şekillendirerek özelliklerini inceledikleri çalışmada optimum özellikleri $600{ }^{\circ} \mathrm{C}$ 'de bir saat sinterleme ile ulaşmışlar ve daha uzun sinter sürelerinin tane büyümesi nedeniyle daha düşük yoğunluğa ve mekanik özelliklere sebep olduğunu tespit etmişlerdir (Şekil 6). Bununla birlikte aşırı uzun olarak tanımlanabilecek sürelerde yapılan sinterleme ile sertliğin, gözenek miktarında oluşacak azalma ile birlikte tekrar yükseldiği görülmüştür (Tablo 2).

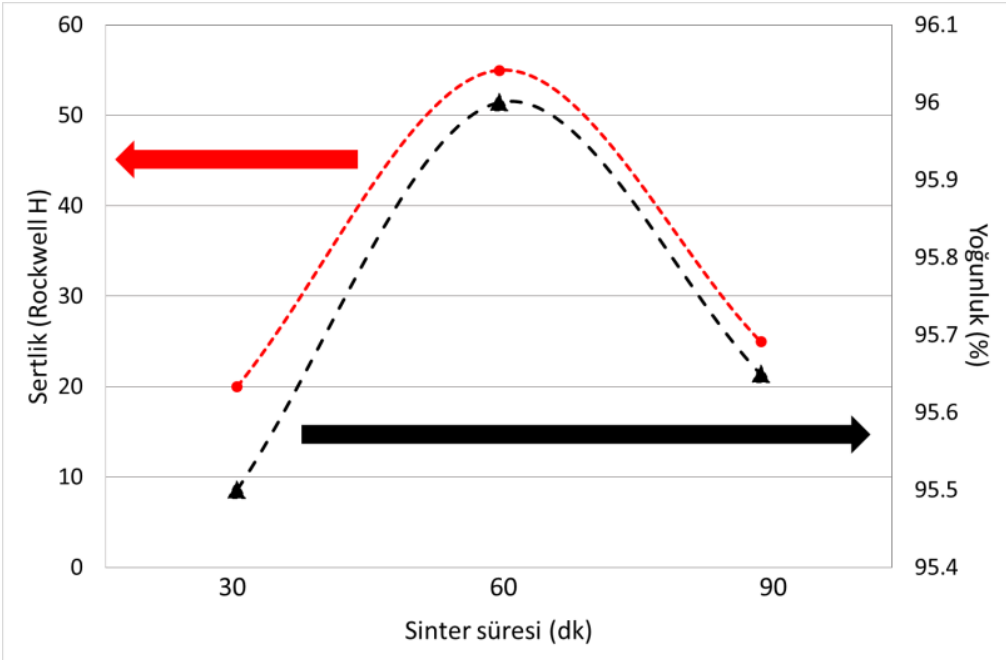

Şekil 6. Sinterleme süresinin saf magnezyumun sertlik ve yoğunluğu üzerine etkisi [39] 
Tablo 2. $500 \mathrm{MPa}$ 'da preslenmiş $600^{\circ} \mathrm{C}$ 'de sinterlenmiş numunelerin mekanik özellikleri [30]

\begin{tabular}{lccc}
\hline \multicolumn{4}{c}{ Sinterleme Süresi } \\
\hline & $\mathbf{4 0}$ dakika & $\mathbf{3 6 0}$ dakika & Döküm eşdĕger \\
\hline Teorik yoğunluk (\%) & $95.1 \pm 1$ & $94.8 \pm 1$ & 99 \\
\hline Sertlik (HRH) & $47.8 \pm 3$ & $65.5 \pm 3$ & 70 \\
\hline Çekme dayanımı (MPa) & $25 \pm 5$ & $72 \pm 5$ & 90 \\
\hline Uzama (\%) & $0.1 \pm 0.1$ & $1.5 \pm 0.1$ & $2-6$ \\
\hline
\end{tabular}

Yapılan çalışmalar saf magnezyumun sinterlenmesinde her ne kadar yüksek yoğunluklara ulaşılsa da mekanik özelliklerin özellikle eğme ve çekme dayanımı gibi özelliklerin istenilen seviyede olmadığını göstermiştir. Yüzey oksidini indirgemek için $\mathrm{Ca}$ sıklıkla tercih edilmektedir. $\mathrm{Mg}$-Ca ikili denge diyagramına göre $\alpha-\mathrm{Mg}$ içinde maksimum Ca çözünürlüğü ağırlıcça \% 1.34'tür [40]. Dolayısıyla, bu değer altında yapılacak Ca katkısının oksit indirgemede faydalı olacağı düşünülebilir. Aynı şekilde Mg$\mathrm{Ca}$ ikili denge diyagramına göre bu iki alaşım arasında magnezyumca zengin ve kalsiyumca zengin 2 ötektik faz bulunmaktadır ve bu fazların oluşum sıcaklıkları $\left(445^{\circ} \mathrm{C}\right.$ ve $\left.516^{\circ} \mathrm{C}\right)$ magnezyumun ergime sıcaklığının altındadır. Ötektik fazların varlığı dolayısıyla düşük miktarda Ca ilavesiyle birlikte bile ötektik bileşime ulaşan bölgelerde düşük miktarda bile olsa sıv1 faz oluşumu meydana gelecek ve sinterleme katı faz sinterlemeden sıvı faz sinterlemeye dönecektir [32]. Wolff vd. [41]belirtilen 2 ötektik bileşime ( $\mathrm{Mg}-7 \mathrm{Ca}$ ve $\mathrm{Ca}-18 \mathrm{Mg}$ ) ait $\mathrm{Mg}-\mathrm{Ca}$ master alaşım tozlarını saf $\mathrm{Mg}$ tozlarına ilave ederek dayanımda büyük artış elde etmişlerdir. Bu aşamada eklenen miktarın ağırlıkça \% 0.6 veya daha az olması gerektiği aynı çalışmada belirtilmiştir. Belli bir miktarın üzerinde eklenen master alaşımın $\mathrm{Mg}_{2} \mathrm{Ca}$ intermetalik fazının oluşumuna sebep olduğu ve mekanik özellikler üzerinde olumsuz etki yapacağı rapor edilmişstir [42].

\section{B. Mg ALAŞIMLARI}

Saf magnezyumun mekanik özellikleri bu malzemenin saf halde yapısal uygulamalarda kullanımını kısıtlayan en önemli etkenlerden biridir. Bu yüzden alaşım elementi ilavesi ile dayanımın artırılması sıklıkla başvurulan bir yöntemdir. Özellikle alüminyum ve çinko magnezyum için sıklıkla kullanılan alaşım elementleridir.

Mg-Al alaşımları özellikle havacılık ve otomotiv alanında tercih edilen alaşımlardır. Döküm alaşımlarında alüminyum dökülebilirliği artırır. Alüminyumun kendisinin de bir hafif alaşım olması alaşım dizaynı sırasında yoğunluk artışının optimum seviyede kalmasını sağlar. Ticari $\mathrm{Mg}$ alaşımlarında $\mathrm{Al}$ oranı genel olarak ağırlıkça \% 2-\% 9 arasındadır [43]. Alüminyum miktarındaki artışla birlikte çekme dayanımı ve dökülebilirlik artarken, oluşan intermetalik $\mathrm{Al}_{12} \mathrm{Mg}_{17}$ fazındaki artışla birlikte süneklik ve darbe dayanımı düşer [44]. Bazı döküm Mg-Al alaşımları Tablo 3'de verilmiştir. Ancak döküm yöntemiyle üretim için avantaj sağlayan bazı alaşım elementleri TM ile üretimde gerekli olmadığı için TM Mg alaşımları, döküm alaşımlardan farklıdır. Örneğin Lu vd.[45] magnezyumu sadece \% $9 \mathrm{Al}$ alaşımlayarak, $375^{\circ} \mathrm{C}$ 'de 4 saat sinterleme ve sonrasında $25: 1$ oranında sicak ekstrüzyon ile $230 \mathrm{MPa}$ akma dayanımı ve \% 5 uzama elde etmişlerdir.

Tablo 3. Döküm Mg-Al alaşımları ve kimyasal bileşimleri [46]

\begin{tabular}{lccccccc}
\hline \multirow{2}{*}{ Alaş1m } & \multicolumn{7}{c}{ Bileşim (ă̆. \%) } \\
\cline { 2 - 8 } & Al & Mn & Si & Zn & Nadir Element & Sr & Mg \\
\hline AM20 & $1.7-2.5$ & $0.20(\min )$ & $0.05(\max )$ & -- & -- & -- & Kalan \\
\hline AM50 & 5 & 0.35 & -- & -- & -- & -- & Kalan \\
\hline AM60 & 6 & 0.35 & -- & -- & -- & -- & Kalan \\
\hline AS21A & 2.25 & 0.35 & 1 & -- & -- & -- & Kalan \\
\hline AS21B & 2.25 & $0.1(\min )$ & 1 & -- & -- & -- & Kalan \\
\hline AS41A & 4.25 & 0.35 & 1 & -- & -- & -- & Kalan \\
\hline AS41B & 4.25 & 0.50 & 1 & -- & -- & -- & Kalan \\
\hline
\end{tabular}


Tablo 3. (devam) Döküm Mg-Al alaşımları ve kimyasal bileşimleri [46]

\begin{tabular}{llllllll}
\hline AZ91A & 9 & 0.13 & -- & 0.7 & -- & -- & Kalan \\
\hline AZ91D & 9 & 0.30 & -- & 0.7 & -- & -- & Kalan \\
\hline AE44 & 4 & 0.25 & -- & -- & 4 & -- & Kalan \\
\hline AJ52A & 5 & 0.4 & & -- & -- & 2 & Kalan \\
\hline AJ62A & 6 & 0.4 & -- & -- & -- & 2.4 & Kalan \\
\hline
\end{tabular}

Mg-Al denge diyagramı incelendiğinde sıvı faz sinterleme için gerekli imkanı sağlayan 2 ötektik faz olduğu görülmektedir. Bunlardan biri $437{ }^{\circ} \mathrm{C}$ diğeri $450{ }^{\circ} \mathrm{C}$ 'de siv1 faz oluşuma sebep olan bu ötektik fazlardan biri alüminyumca diğeri magnezyumca zengindir. TM ile sinterleme işlemlerinde elementel tozların kullanılması durumunda sinterleme sıcaklığ $1437^{\circ} \mathrm{C}$ 'ye ulaştı̆̆ında ilk geçici sıvı fazın oluşması beklenmektedir [47]. Dolayısıyla $\mathrm{Al}$ içeriğinden bağımsız olarak $\mathrm{Mg}$-Al alaşımlarının $437^{\circ} \mathrm{C}$ üzerinde yapılacak tüm sinterleme işlemlerinin sıvı faz sinterleme olması beklenmektedir. Mekanik alaşımlama yöntemi de Mg-Al alaşımlarının üretiminde kullanılacak tozların önalaşımlanması için kullanılabilir bir yöntemdir. Singh vd. [48] Mg içine \% 30, \% 40 ve \% $50 \mathrm{Al}$ (\% at.) ilavesi ile mekanik alaşımlama işlemi sonrasında \% 30 ve $\% 40 \mathrm{Al}$ ilavesinde $\alpha-\mathrm{Al}$ ve $\beta-\mathrm{Al}_{12} \mathrm{Mg}_{17}$ oluşumu tespit etmişler, yüksek Al ilavesinde ise ek olarak $\mathrm{Al}_{2} \mathrm{Mg}_{3}$ fazı olduğunu rapor etmişlerdir. $\mathrm{Mg}$-Al alaşımları ile ilgili olarak literatürde elde edilen bazı sonuçlar Tablo 4'te özetlenmiştir.

Tablo 4. Bazı Mg-Al alaşımları ile ilgili TM çalışmalarında elde edilen sonuçlar

\begin{tabular}{|c|c|c|c|c|c|}
\hline Alaşım & Toz tipi & Yöntem & $\begin{array}{l}\text { Sinter } \\
\text { Sıcaklığı }\end{array}$ & Sonuç & Ref \\
\hline Mg-9Al & Elementel & $\begin{array}{l}\text { Press-Sinter } \\
(400 \mathrm{MPa})\end{array}$ & $\begin{array}{l}\text { Katı faz } \\
\text { sinterleme } \\
\left(427^{\circ} \mathrm{C}\right) \\
\text { Siv1 Faz } \\
\text { sinterleme } \\
\left(470^{\circ} \mathrm{C}\right)\end{array}$ & $\begin{array}{l}\text { Alaşım sinter sonrası } 420 \\
{ }^{\circ} \mathrm{C} \text { 'de } 10: 1 \text { oranında } \\
\text { ekstrüde edilmiştir. Çekme } \\
\text { dayanımı sırasıyla } 327 \text { ve } \\
345 \mathrm{MPa} \text { dır. }\end{array}$ & [49] \\
\hline $\mathrm{Mg}-8 \mathrm{Al}$ & Elementel & $\begin{array}{l}\text { Press-Sinter } \\
(200 \mathrm{MPa})\end{array}$ & $\begin{array}{l}550^{\circ} \mathrm{C}, \\
585^{\circ} \mathrm{C}, \\
620^{\circ} \mathrm{C}\end{array}$ & $\begin{array}{l}\text { Artan sinter sicaklığıyla } \\
\text { birlikte } \\
\text { parametrelerinde } \\
\text { tespit edilmiştir. }\end{array}$ & {$[50]$} \\
\hline $\mathrm{Mg}-9 \mathrm{Al}$ & Elementel & $\begin{array}{l}\text { Seçici Lazer } \\
\text { Sinterleme }\end{array}$ & -- & $\begin{array}{l}4 \text { ayrı enerji girdisi ile } \\
\text { üretilen alaşımlardan elde } \\
\text { edilen en yüksek yoğunluk } \\
\% 95.7 \text { TY ve en yüksek } \\
\text { çekme dayanımı } 274 \mathrm{MPa} \\
\text { olarak ölçülmüştür. }\end{array}$ & [51] \\
\hline $\begin{array}{l}\mathrm{Mg} \\
\mathrm{Mg}-3 \mathrm{Al} \\
\mathrm{Mg}-6 \mathrm{Al} \\
\mathrm{Mg}-9 \mathrm{Al}\end{array}$ & Elementel & $\begin{array}{l}\text { Seçici Lazer } \\
\text { Sinterleme }\end{array}$ & -- & $\begin{array}{l}\text { Daha yüksek lazer tarama } \\
\text { hızlarında daha yüksek } \\
\text { gözeneklilik, alüminyum } \\
\text { miktarı arttıça } \\
\text { gözeneklilikte artış, en } \\
\text { yüksek yoğunluk \% } 97.1 \\
\text { (saf Mg) olarak tespit } \\
\text { edilmiştir. }\end{array}$ & {$[52]$} \\
\hline $\mathrm{Mg}-8 \mathrm{Al}$ & Elementel & $\begin{array}{l}\text { Press-Sinter } \\
(500 \mathrm{MPa})\end{array}$ & $\begin{array}{c}600{ }^{\circ} \mathrm{C}-40 \\
\text { dakika }\end{array}$ & $\begin{array}{lrr}\text { Yoğunluk } & 1.73 & \text { gr/cm } \\
\text { sertlik 86.7 } & \text { HRH } & \text { olarak } \\
\text { ölçülmüştür. } & \text { Azot } \\
\text { atmosferinde } & \text { yapılan } \\
\text { sinterleme ile } & \text { Argona } \\
\text { nispeten daha } & \text { düşük } \\
\text { gözenekliliğe ulaşıllmıştır. }\end{array}$ & [30] \\
\hline
\end{tabular}


Tablo 4. (devam) Bazı Mg-Al alaşımları ile ilgili TM çalışmalarında elde edilen sonuçlar

\begin{tabular}{|c|c|c|c|c|c|}
\hline $\mathrm{Mg}-12 \mathrm{Al}$ & Elementel & $\begin{array}{l}\text { Sicak presleme } \\
\left(23^{\circ} \mathrm{C}-150^{\circ} \mathrm{C}\right) \\
- \\
(489 \mathrm{MPa})\end{array}$ & $\begin{array}{c}400{ }^{\circ} \mathrm{C} \text { ila } 475 \\
{ }^{\circ} \mathrm{C}\end{array}$ & \begin{tabular}{lrr} 
En yüksek & \multicolumn{2}{r}{ sinterleme } \\
sıcaklığında 150 & $\mathrm{MPa}$ \\
eğme dayanımı elde & eld \\
edilmiştir. & Sicak \\
kompaktlama ile daha iyi \\
mekanik özelliklere \\
ulaşılmıştır.
\end{tabular} & [37] \\
\hline $\begin{array}{l}\text { AMX602 } \\
\text { (Mg-6Al- } \\
0.5 \mathrm{Mn}-2 \mathrm{Ca})\end{array}$ & Önalaşımlı & $\begin{array}{l}\text { Press-Sinter } \\
(300 \mathrm{MPa}) \\
\text { Spark Plazma } \\
\text { Sinterleme } \\
\end{array}$ & $\begin{array}{c}200{ }^{\circ} \mathrm{C}-\mathrm{SPS} \\
\text { basinc1 } 10 \\
\mathrm{MPa}- \\
4 \mathrm{~Pa} \text { vakum } \\
\end{array}$ & $\begin{array}{l}575^{\circ} \mathrm{C} \text { sicaklığında ypılan } \\
\text { ekstrüzyon sonras1 } 450 \\
\mathrm{MPa} \text { çekme dayanımına } \\
\text { ulaşılmıştır. }\end{array}$ & $\begin{array}{l}{[53],} \\
{[54]}\end{array}$ \\
\hline $\begin{array}{l}\mathrm{Mg}-9 \mathrm{Al} \\
\mathrm{Mg}-11.3 \mathrm{Al}- \\
2 \mathrm{Ni} \\
\mathrm{Mg}-14.8 \mathrm{Al}- \\
5 \mathrm{Ni} \\
\mathrm{Mg}-18.3 \mathrm{Al}- \\
8 \mathrm{Ni}\end{array}$ & Elementel & $\begin{array}{l}\text { Sicak presleme } \\
\left(450^{\circ} \mathrm{C}-30 \mathrm{dk}\right)\end{array}$ & $600^{\circ} \mathrm{C}-20 \mathrm{dk}$ & $\begin{array}{l}\text { Nikel ilavesi } \text { ile } \text { yüksek } \\
\text { sicaklık (150 C) basma } \\
\text { dayanımı kademeli olarak } \\
\text { artmıştır. \% } 8 \mathrm{Ni} \text { ilavesinde } \\
235 \mathrm{MPa} \text { basma dayanımı } \\
\text { elde edilmiştir. }\end{array}$ & [55] \\
\hline AZ91 & Önalaşımlı & $\begin{array}{l}\text { Press-Sinter } \\
(880 \mathrm{MPa})\end{array}$ & $\begin{array}{c}400^{\circ} \mathrm{C}-1.5 \\
\text { saat-Argon } \\
\text { atmosferinde }\end{array}$ & 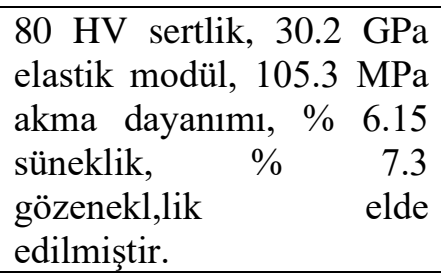 & [56] \\
\hline AZ91 & Önalaşımlı & $\begin{array}{l}\text { Spark Plazma } \\
\text { Sinterleme }\end{array}$ & $\begin{array}{c}310-500{ }^{\circ} \mathrm{C} \\
\text { arasinda }\end{array}$ & 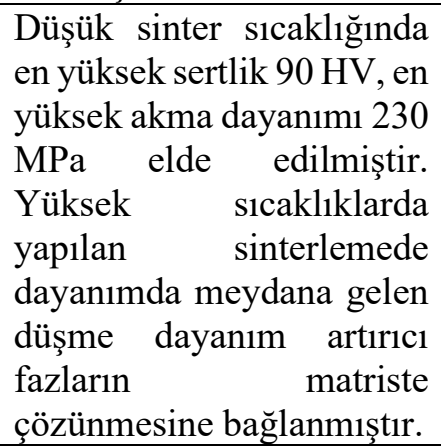 & [57] \\
\hline Mg-1Al-1Sn & Elementel & $\begin{array}{l}\text { Press-Sinter } \\
(600 \mathrm{MPa})\end{array}$ & $\begin{array}{c}630-2 \text { saat } \\
\text { argon- } 350{ }^{\circ} \mathrm{C}- \\
\text { ekstrüzyyon }\end{array}$ & $\begin{array}{l}161 \mathrm{MPa} \text { akma dayanımı, } \\
236 \mathrm{MPa} \text { çekme dayanımı, } \\
\% \quad 16.7 \text { süneklik elde } \\
\text { edilmiştir. }\end{array}$ & {$[58]$} \\
\hline AE42 & Önalaşımlı & $\begin{array}{l}\text { Spark Plazma } \\
\text { Sinterleme }\end{array}$ & $\begin{array}{c}450{ }^{\circ} \mathrm{C}-500 \\
{ }^{\circ} \mathrm{C}-550^{\circ} \mathrm{C}\end{array}$ & $\begin{array}{l}\text { \% 1-1.5 arası gözeneklilik } \\
\text { tespit edilmiştir ve sinter } \\
\text { S1caklığı ile gözeneklilik } \\
\text { arasında önemli bir ilişki } \\
\text { olmadığ gözlenmiştir. En } \\
\text { yüksek akma dayanımı } 450 \\
\text { C'de elde edilmiş olup } 168 \\
\text { MPa'dır. }\end{array}$ & [59] \\
\hline
\end{tabular}

\section{SONUC}

$\mathrm{Bu}$ çalışmada uluslararası literatürde saf $\mathrm{Mg}$ ve $\mathrm{Mg}$-Al alaşımları ile ilgili çalışmalarda elde edilen bulgular özetlenmiştir. Çalışmaların sonuçlarına göre saf $\mathrm{Mg}$ düşük dayanımı nedeniyle yapısal 
uygulamalarda kullanılmaya uygun olmasa bile biyouyumluluk özelliği sebebiyle biyomedikal malzeme olarak kullanılabilir niteliktedir. Ancak magnezyumun plastik deformasyon imkanının kısıtlı olması bu malzeme için TM süreçlerinin kullanılmasını daha önemli hale getirmektedir. TM işlemlerinde ise yüzey oksidinin termal bariyer etkisi göstermesi nedeniyle sınırlı kullanım imkanı bulunmaktadır. Yüzey oksidinin kırılması için oksijene afinitesi magnezyumdan daha fazla olan elementlerin mikro düzeyde katılması bir çözüm olarak değerlendirilmektedir. Mg-Al alaşımlarının oda sıcaklığı dayanımları nispeten ikincil işlemlerle belli değerin üzerine çıkılabilse bile bu alaşımlarda dayanım artırıcı faz olan $\mathrm{Al}_{12} \mathrm{Mg}_{17}$ 'nin düşük sıcaklıklarda ergimesi sebebiyle yüksek sıcaklıklarda dayanımı henüz düşüktür. Belirtilen sebeplerle $\mathrm{Mg}$-Al alaşımlarının otomotiv ve havacılık sektöründe yüksek sıcaklık dayanımı gerektirmeyen parçaların üretiminde kullanılabilir olduğu ve özellikle karmaşık şekilli parçaların üretim süreçlerinde TM işlemlerinin kullanılmasıyla iyi bir aday malzeme olduğu değerlendirilmektedir.

\section{KAYNAKLAR}

[1] US Department of Energy, "Global Transportation Energy Consumption: Examination of Scenarios to 2040 using ITEDD," 2017. [Online]. Erişim: https://www.eia.gov/analysis/studies/transportation/scenarios/pdf/globaltransportation.pdf

[2] M. Höök ve X. Tang, "Depletion of fossil fuels and anthropogenic climate change-A review," Energy Policy, c. 52, ss. 797-809, 2013.

[3] J. C. Escobar, E. S. Lora, O. J. Venturini, E. E. Yáñez, E. F. Castillo, and O. Almazan, "Biofuels: Environment, technology and food security," Renewable and Sustainable Energy Reviews, c. 13, s. 67, ss. 1275-1287, 2009.

[4] P. Morone ve L. Cottoni, "Biofuels," in Handbook of Biofuels Production, 2. bask1, R. Luque, C. Lin, K. Wilson, and J. Clark, Eds. Cambridge: Elsevier, 2016, ss. 61-83.

[5] A. Jambor ve M. Beyer, "New cars - new materials," Materials \& Design, c. 18, s. 4-6, ss. 203-209, 1997.

[6] "Light-Duty Automotive Technology, Carbon Dioxide Emissions, and Fuel Economy Trends : 1975 Through 2011," 2014.

[7] M. L. Anderson ve M. Auffhammer, "Pounds that kill: The external costs of vehicle weight," Review of Economic Studies, c. 81, s. 2, ss. 535-571, 2013.

[8] W. L. Dalmijn ve T. P. R. De Jong, "The development of vehicle recycling in Europe: Sorting, shredding, and separation," JOM, c. 59, s. 11, ss. 52-56, 2007.

[9] A. I. Taub ve A. A. Luo, "Advanced lightweight materials and manufacturing processes for automotive applications," MRS Bulletin, c. 40, s. 12, ss. 1045-1054, 2015.

[10] P. Seyfried, E. J. M. Taiss, A. C. Calijorne, F.-P. Li, and Q.-F. Song, "Light weighting opportunities and material choice for commercial vehicle frame structures from a design point of view," Advances in Manufacturing, c. 3, s. 1, ss. 19-26, 2015.

[11] A. H. Musfirah ve A. . Jaharah, "Magnesium and Aluminum Alloys in Automotive Industry," Journal of Applied Science Research, c. 8, s. 9, ss. 4865-4875, 2012.

[12] G. S. Cole ve A. M. Sherman, "Light weight materials for automotive applications," Materials Characterization, c. 35, s. 1, ss. 3-9, 1995. 
[13] I. Polmear, D. StJohn, J. F. Nie, and M. Qian, "The Light Metals," in Light Alloys, 5. bask1., Boston: Elsevier, 2017, ss. 1-29.

[14] M. K. Kulekci, "Magnesium and its alloys applications in automotive industry," The International Journal of Advanced Manufacturing Technology, c. 39, s. 9, ss. 851-865, 2008.

[15] W. Miller ve diğ. "Recent development in aluminium alloys for the automotive industry," Materials Science and Engineering: A, c. 280, s. 1, ss. 37-49, 2000.

[16] I. Polmear, "Aluminium Alloys--A Century of Age Hardening," Materials forum, c. 28, ss. 1$14,2004$.

[17] M. Easton, W. Qian Song, ve T. Abbott, "A comparison of the deformation of magnesium alloys with aluminium and steel in tension, bending and buckling," Materials \& Design, c. 27, s. 10, ss. 935946, 2006.

[18] G. Yarkadaş, L. C. Kumruoğlu, ve H. Şevik, "The effect of Cerium addition on microstructure and mechanical properties of high pressure die cast Mg-5Sn alloy," Materials Characterization, c. 136, s. November 2017, ss. 152-156, 2018.

[19] G. Germen, G. Yarkadaş, ve H. Şevik, "Influence of strontium addition on the wear behavior of Mg-3Al-3Sn alloys produced by gravity casting," Materials Testing, c. 57, s. 11-12, ss. 997-1000, 2015.

[20] A. Gökçe, "Metallurgical Assessment of Novel Mg-Sn-La Alloys Produced by High-Pressure Die Casting," Metals and Materials International, 2019, DOI:10.1007/s12540-019-00539-1.

[21] S. Özarslan, H. Şevik, ve İ. Sorar, "Microstructure, mechanical and corrosion properties of novel $\mathrm{Mg}-\mathrm{Sn}-\mathrm{Ce}$ alloys produced by high pressure die casting," Materials Science and Engineering: C, c. 105, p. 110064, 2019.

[22] F. Bonollo, N. Gramegna, ve G. Timelli, "High-pressure die-casting: Contradictions and challenges," Jom, c. 67, s. 5, ss. 901-908, 2015.

[23] B. L. Mordike ve T. Ebert, "Magnesium," Materials Science and Engineering: A, c. 302, s. 1, ss. $37-45,2001$.

[24] A. Gökçe, F. Fındık, ve A. O. Kurt, "Alüminyum ve Alaşımlarının Toz Metalurjisi İşlemleri Powder Metallurgy Processing of Aluminum Alloys," Engineer\&Machinery, c. 58, s. 686, ss. 21-47, 2017.

[25] R. M. German, Sintering: from Empirical Observations to Scientific Principles, Del Mar, CA, USA: Elsevier, 2014.

[26] "Economic considerations for powder metallurgy structural parts," Powder Metallurgy Review. [Online]. Erişim: https://www.pm-review.com/introduction-to-powder-metallurgy/economicconsiderations-for-powder-metallurgy-structural-parts/.

[27] T. Schubert ve di $\breve{g}$, "P/M aluminium structural parts for automotive application," in Euro PM 2004, 2004, ss. 627-632.

[28] H. . Yao, Y. Li, ve A. T. . Wee, "An XPS investigation of the oxidation/corrosion of melt-spun Mg,” Applied Surface Science, c. 158, s. 1-2, ss. 112-119, 2000.

[29] P. Burke, C. Petit, S. Yakoubi, ve G. J. Kipouros, "Thermal Effects of Calcium and Yttrium Additions on the Sintering of Magnesium Powder," Magnesium Technology 2011, ss. 481-484, 2016. 
[30] P. Burke, "Investigation of the Sintering Fundamentals of Magnesium," MS Thesis, Dept. of Process Engineering, Dalhousie University, Halifax, Canada, 2011.

[31] R. Yılmaz, A. Gökçe, ve H. Kapdibaş, "The Effect of Ferro-Molybdenum Addition on the Microstructure and Mechanical Properties of Sintered Steel," Advanced Materials Research, c. 23, ss. 71-74, 2007.

[32] A. Gökçe, F. Findik, ve A. O. Kurt, "Effects of Sintering Temperature and Time on the Properties of Al-Cu PM Alloy," Practical Metallography, c. 54, s. 8, ss. 533-551, 2017.

[33] R. N. Lumley, T. B. Sercombe, ve G. B. Schaffer, "Surface oxide and the role of magnesium during the sintering of aluminum," Metallurgical and Materials Transactions A, c. 30, s. 2, ss. 457-463, 1999.

[34] P. Burke, J. Li, ve G. J. Kipouros, "DSC and FIB/TEM investigation of calcium and yttrium additions in the sintering of magnesium powder," Canadian Metallurgical Quarterly, c. 55, s. 1, ss. 45$52,2016$.

[35] O. S. Gökçe, "Sıcak Pres ile Partikül Takviyeli Magnezyum Kompozitlerin Üretimi ve Kaplanması," Yüksek lisans tezi, Metalurji ve Malzeme Mühendisliği. Ana bilim dalı, Kocaeli Üniversitesi, Kocaeli, Turkey, 2018.

[36] N. Taşkın, "Magnezyum Talaşlarından Malzeme Üretimi," Yüksek lisans tezi, Metalurji ve Malzeme Mühendisliği. Ana bilim dalı, İstanbul Teknik Üniversitesi, İstanbul, Turkey, 2012.

[37] T. Iwaoka ve M. Nakamura, "Effect of Compaction Temperature on Sinterability of Magnesium and Aluminum Powder Mixtures by Warm Compaction Method," Materials Transactions, c. 52, s. 5, ss. 943-947, 2011.

[38] M. Březina ve diğ., "Characterization of Powder Metallurgy Processed Pure Magnesium Materials for Biomedical Applications," Metals, c. 7, s. 11, p. 461, 2017.

[39] P. Burke, G. J. Kipouros, D. Fancelli, ve V. Laverdiere, "Sintering Fundamentals of Magnesium Powders," Canadian Metallurgical Quarterly, c. 48, s. 2, ss. 123-132, 2014.

[40] A. A. Nayeb-Hashemi ve J. B. Clark, "The Ca-Mg (Calcium-Magnesium) system," Bulletin of Alloy Phase Diagrams, c. 8, s. 1, ss. 58-65, 1987.

[41] M. Wolff, T. Ebel, ve M. Dahms, "Sintering of magnesium," Advanced Engineering Materials, c. 12 , s. 9, ss. 829-836, 2010.

[42] Z. Li, X. Gu, S. Lou, ve Y. Zheng, "The development of binary Mg-Ca alloys for use as biodegradable materials within bone," Biomaterials, c. 29, s. 10, ss. 1329-1344, 2008.

[43] T. B. Abbott, M. A. Easton, ve C. H. Caceres, "Designing with Magnesium," in Handbook of Mechanical Alloy Design, s. September, G. E. Totten, L. Xie, and K. Funatani, Eds. CRC Press, 2004, ss. 487-538.

[44] H. Westengen, "Magnesium alloys for structural applications ; recent advances," Le Journal de Physique IV, c. 03, s. C7, ss. C7-491-C7-501, 1993.

[45] L. Lu, C. Y. H. Lim, ve W. M. Yeong, "Effect of reinforcements on strength of Mg9\% Al composites," Composite Structures, c. 66, s. 1-4, ss. 41-45, 2004. 
[46] C. Moosbrugger, Ed., Engineering Properties of Magnesium Alloys, 1. bask1, Ohio, USA: ASM International, 2017.

[47] A. Gökçe, F. Findik, ve A. O. Kurt, "Sintering and aging behaviours of Al4CuXMg PM alloy," Canadian Metallurgical Quarterly, c. 55, s. 4, ss. 391-401, 2016.

[48] D. Singh, C. Suryanarayana, L. Mertus, ve R.-H. Chen, "Extended homogeneity range of intermetallic phases in mechanically alloyed $\mathrm{Mg}-\mathrm{Al}$ alloys," Intermetallics, c. 11, s. 4, ss. 373-376, 2003.

[49] W. Xie, Y. Liu, D. S. Li, J. Zhang, Z. W. Zhang, ve J. Bi, "Influence of sintering routes to the mechanical properties of magnesium alloy and its composites produced by PM technique," Journal of Alloys and Compounds, c. 431, s. 1-2, ss. 162-166, 2007.

[50] J. Chen, C.-G. Bao, Y. Wang, J.-L. Liu, ve C. Suryanarayana, "Microstructure and Lattice Parameters of AlN Particle-Reinforced Magnesium Matrix Composites Fabricated by Powder Metallurgy," Acta Metallurgica Sinica (English Letters), c. 28, s. 11, ss. 1354-1363, 2015.

[51] X. Niu, H. Shen, ve J. Fu, "Microstructure and mechanical properties of selective laser melted Mg-9 wt\%Al powder mixture," Materials Letters, c. 221, ss. 4-7, 2018.

[52] X. Niu, H. Shen, G. Xu, L. Zhang, J. Fu, ve X. Deng, "Effect of aluminium content and processing parameters on the microstructure and mechanical properties of laser powder-bed fused magnesium-aluminium $(0,3,6,9 \mathrm{wt} \%)$ powder mixture," Rapid Prototyping Journal, p. RPJ-08-20180213, 2019.

[53] E. A. Nyberg, S. R. Agnew, N. R. Neelameggham, ve M. O. Pekguleryuz, Magnesium Technology 2009. Wiley, 2009.

[54] K. Kondoh, E.-S. A. Hamada, H. Imai, J. Umeda, ve T. Jones, "Microstructures and mechanical responses of powder metallurgy non-combustive magnesium extruded alloy by rapid solidification process in mass production," Materials \& Design, c. 31, s. 3, ss. 1540-1546, 2010.

[55] L. Hou et al., "Microstructure and mechanical properties at elevated temperature of Mg-Al-Ni alloys prepared through powder metallurgy," Journal of Materials Science \& Technology, c. 33, s. 9, ss. 947-953, 2017.

[56] M. Razavi, M. H. Fathi, ve M. Meratian, "Microstructure, mechanical properties and biocorrosion evaluation of biodegradable AZ91-FA nanocomposites for biomedical applications," Materials Science and Engineering: A, c. 527, s. 26, ss. 6938-6944, 2010.

[57] M. Mondet, E. Barraud, S. Lemonnier, J. Guyon, N. Allain, ve T. Grosdidier, "Microstructure and mechanical properties of AZ91 magnesium alloy developed by Spark Plasma Sintering," Acta Materialia, c. 119, ss. 55-67, 2016.

[58] M. Rashad, F. Pan, M. Asif, ve A. Tang, "Powder metallurgy of Mg-1\%Al-1\%Sn alloy reinforced with low content of graphene nanoplatelets (GNPs)," Journal of Industrial and Engineering Chemistry, c. 20, s. 6, ss. 4250-4255, 2014.

[59] P. Minárik, J. Stráský, J. Veselý, F. Lukáč, B. Hadzima, ve R. Král, “AE42 magnesium alloy prepared by spark plasma sintering," Journal of Alloys and Compounds, c. 742, ss. 172-179, 2018. 